\title{
Impact behaviour of acrylonitrile-butadiene-styrene after temperature and humidity load
}

\author{
Lenka Hylova ${ }^{1, *}$, Miroslav Manas ${ }^{1}$ \\ ${ }^{1}$ Tomas Bata University in Zlin, nam. T. G. Masaryka 5555, 76001 Zlin, Czech Republic
}

\begin{abstract}
This study deals with acrylonitrile-butadiene-styrene (ABS) which was subjected the drop-weight test before and after temperature and humidity load. ABS is an engineering plastic and also an important engineering terpolymer, which has butadiene part uniformly distributed through the acrylonitrile-styrene matrix and is commonly used in production of automotive interior components. The injection moulded ABS samples were subjected the penetration test at fall height $100 \mathrm{~J}$ before and after temperature and humidity load and the results were subsequently evaluated and discussed. It was found out that ABS after temperature and humidity load has lower impact resistance.
\end{abstract}

\section{Introduction}

Acrylonitrile-butadiene-styrene (ABS) is an engineering plastic and also an important engineering terpolymer, which has butadiene part uniformly distributed through the acrylonitrile-styrene matrix. ABS was commercialized at the latter of 1940s by U.S. Rubber and originally was made by blending of polystyrene-coacrylonitrile (SAN) and NBR acrylonitrile-butadiene rubber (NBR), while nowadays ABS of the graft-type is made by copolymerization of styrene and acrylonitrile monomers in the rubber presence. Some of SAN is grafted to the rubber during the polymerization process and the grafted SAN behaves as a dispersing agent. The rubber phase, which is the part of ABS (generally polybutadiene grafted with SAN) is dispersed in the form of spherical particles in grafted SAN. Physical properties of ABS are influenced by the rubber particle size and content, molecular weight of SAN matrix and also by the grafting degree. The origin of ABS can be set to mid1940s. Acrylonitrile-styrene copolymer was used since 1940s and the disadvantages of this copolymer led to the incorporation of third monomer namely butadiene rubber, which imparted higher impact resistance and higher strength to this terpolymer. ABS has great mechanical properties, chemical resistance, excellent toughness, easy processing ability, good dimensional stability, durability, cheapness and low coefficient of thermal expansion. The low mechanical strength, vulnerability to environmental conditions and non-conductivity are the disadvantages of ABS. It is also possible to enhance mechanical properties such as tensile strength, hardness and flexural modulus of ABS using fibre-reinforcement. This polymeric material has various application as in the architecture, construction, computer and business equipment, personal care products, toys, medical devices and in automotive interior components [1-3].

Brazilian scientists investigated three types of commercial ABS, namely GP (ABS for general-purpose use), $\mathrm{HI}$ (an ABS high impact) and HH (ABS high heat resistance). They studied activation energy of all three ABS and they realized that it is much higher than reported in the literature. One reason can be the fact that ABS terpolymer is produced worldwide by a large number of producers and for different application of use. They also found out that ABS HH is a little more thermally resistant than ABS HI and much more than ABS GP because of its highest acrylonitrile content. ABS $\mathrm{HI}$ and $\mathrm{ABS} \mathrm{HH}$ also exibit high activation energy because of high butadiene content, this is probably because the SAN matrix is directly bonded to butadiene and the liberation of butadiene is very difficult during the degradation reaction [1].

The scientists from China dealt with the influence of polybutadiene-grafted styrene-acrylonitrile (PB-g-SAN) impact modifiers content on mechanical behaviour and morphology of ABS blends. They found out a big influence of PB-g-SAN content on impact strength, the higher PB-g-SAN content, the higher impact strength is, unlike the flexural strength, flexural modulus, melt flow index, tensile strength, and Rockwell hardness decrease with the increase of PB-g-SAN content [4].

M.A. Peydro, F. Pares, R. Navarro and S. SanchesCaballero dealt with ABS contaminated with LDPE which obtained using a twin-screw extruder. Four ABS/LDPE blends of $1,3,4$ and $8 \%$ of LDPE were obtained and then other ABS/LDPE blends with adding of styrene-ethylene/butadiene-styrene (SEBS) was made

Corresponding author: hylova@utb.cz 
in $1,2,4$ and $8 \mathrm{wt} \%$ of SEBS. The flat specimens were injection moulded and subsequently tested. It was found that the higher content of LDPE, the lower tensile strength, tensile modulus, elongation at break, Charpy notched impact strength are, unlike the shrinkage increases with the content of LDPE. After adding of SEBS, elongation at break and Charpy notched impact strength increase with the content of SEBS and also the shrinkage slightly decreases [5].

A team of Chinese scientists investigated impact behaviour of two ABS samples. ABS-1 sample was toughened with $10 \mathrm{wt} \%$ compounded rubber (low-cis PB rubber/styrene-butadiene block copolymer) and ABS-2 sample was made with $12 \mathrm{wt} \%$ linear random styreneisoprene-butadiene rubber (SIBR) as a toughening modifier. ABS-2 has much higher impact strength and elongation at break than ABS-1 sample, unlike ABS-1 has higher tensile strength and break strength in comparison with ABS-2 sample [6].

Cooperation of Chinese and Canadian scientists has brought interesting results. These scientists dealt with ABS blends with a constant rubber concentration of 15 $\mathrm{wt} \%$ compounded with polybutadiene-grafted styreneacrylonitrile (PBD-g-SAN) impact modifiers with SAN resin in a twin-screw extruder. The blend with small rubber particles is called ABS-S and with large rubber particles ABS-L. The ABS-L has slightly lower yield strength in comparison with ABS-S, while ABS-S has more than four times lower impact strength than ABS-L which shows that small rubber particles with the diameter of $92 \mathrm{~nm}$ cannot toughen SAN resin [7].

This study can bring a big benefit for the deeper knowledge about ABS after temperature and humidity load, which is useful to apply for both the indoor and outdoor applications of this material.

\section{Experimental}

ABS was used as the basic polymer material (STAREX ABS, HF-06601W). An ARBURG Allrounder 470H Advance Injection moulding machine was used for sample preparation, with the processing conditional to comply with acrylonitrile-butadiene styrene (ABS) producer's recommendations, as can be seen in Tab. 1 . The samples were in the shape of plates with dimensions $100 \times 100 \times 3 \mathrm{~mm}$ according to ISO $6603-2$.

Table 1. Setting of injection moulding machine parameters

\begin{tabular}{|l|l|}
\hline Injection Parameters & Values \\
\hline Injection Pressure $[\mathrm{MPa}]$ & 70 \\
\hline Injection velocity $\left[\mathrm{mm} \cdot \mathrm{s}^{-1}\right]$ & 40 \\
\hline Holding Pressure $[\mathrm{MPa}]$ & 65 \\
\hline Cooling Time $[\mathrm{s}]$ & 17 \\
\hline Mould Temperature $\left[{ }^{\circ} \mathrm{C}\right]$ & 40 \\
\hline Melt Temperature $\left[{ }^{\circ} \mathrm{C}\right]$ & 225 \\
\hline
\end{tabular}

A part of injection moulded samples was put into the climatic chamber, type DISCOVERY from company Angelantoni. These samples were 168 hours in environment at temperature $75{ }^{\circ} \mathrm{C}$ and humidity $98 \%$. After this time the samples were cooled on $23{ }^{\circ} \mathrm{C}$ and $50 \%$ of humidity with rate of cooling $10^{\circ} \mathrm{C}$ per hour and rate of humidity decreasing $10 \%$ per hour.

Drop weight test carried out on temperature and humidity loaded samples after 24 hours acclimatization at ambient temperature $\left(23{ }^{\circ} \mathrm{C}\right)$ and humidity $(50 \%)$. Gain results were compared with non-loaded samples, which was tested at the same conditions. For these tests drop weight test machine HIT230F from company Zwick was used. The test carried out at $100 \mathrm{~J}$ impact energy of penetrator, falling surface of penetrator has shape of hemisphere with diameter $20 \mathrm{~mm}$. Test was performed according to ISO 6603-2. TestExpert II was used for evaluation of results, which were maximum impact force and all consumed work for whole deformation. At the end crack surface after the test was evaluated.
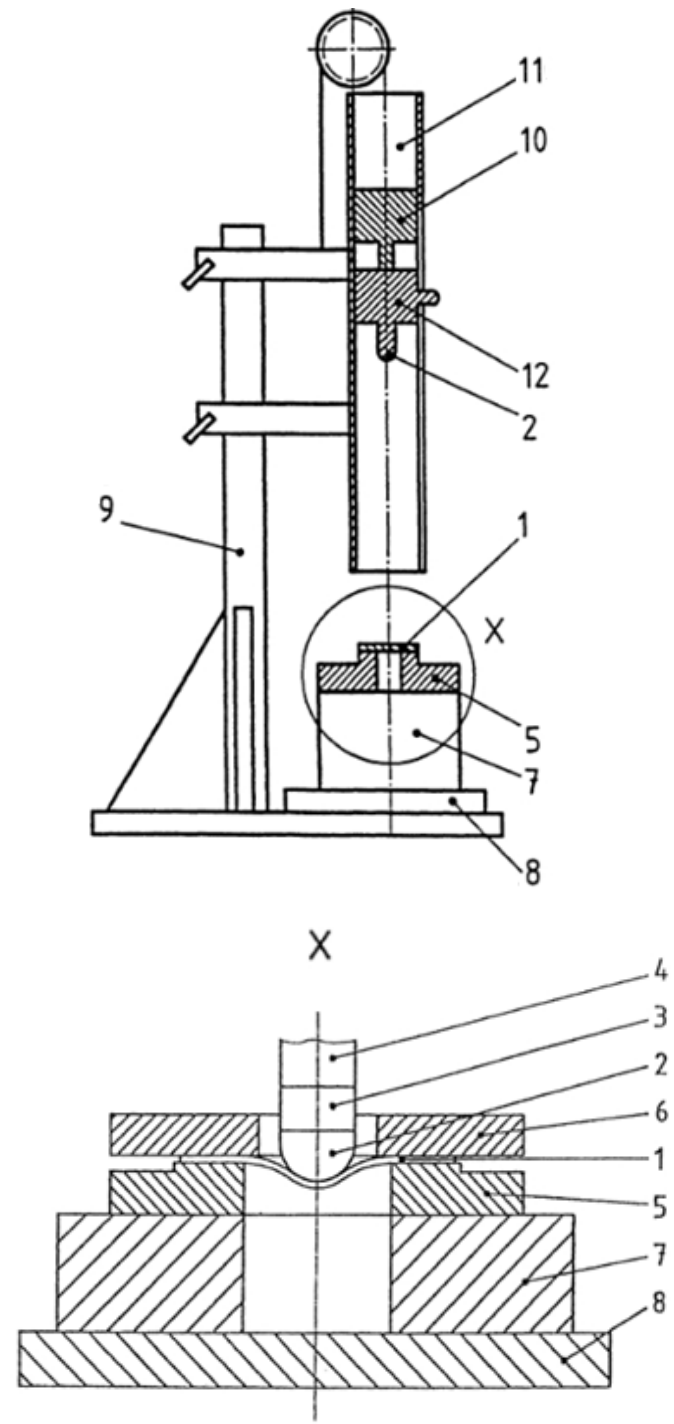

Fig. 1. Falling-dart system.

1 - Test specimen; 2 - Hemispherical striker tip $10 \mathrm{~mm} ; 3$ Force sensor; 4 - Shaft; 5 - Test specimen support; 6 Clamping ring (optional); 7 - Base; 8 - Acoustic isolation 
(optional); 9 - Stand for falling-dart system; 10 - Holding and release system for weighted striker; 11 - Guide shaft for weighted striker; 12 - Weighted striker $23,77 \mathrm{~kg}$.

\section{Results and discussion}

This study is concentrated on comparison ABS before and after temperature and humidity load. Injection moulded ABS samples were penetrated by penetrator with potential energy $100 \mathrm{~J}$ before and after load.

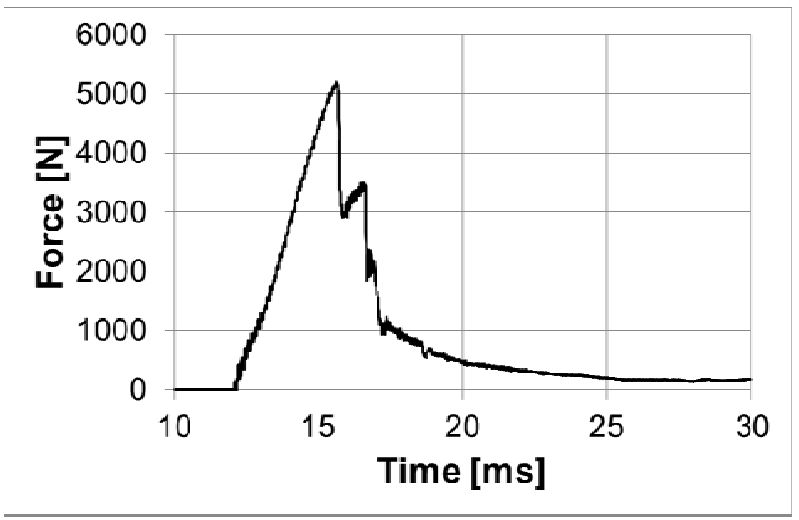

Fig. 2. ABS force record in time before temperature and humidity loading.

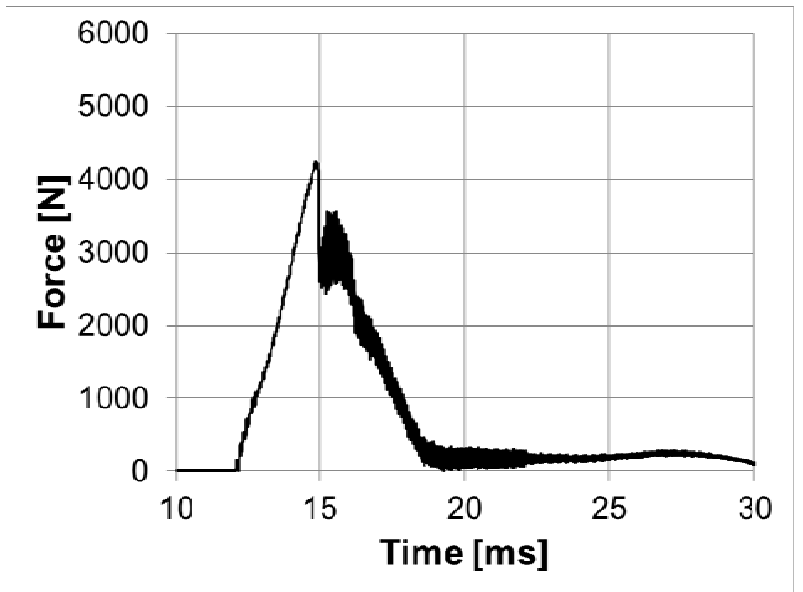

Fig. 3. ABS force record in time after temperature and humidity loading.

From the Figure 2 and 3 it is clearly visible that ABS after temperature and humidity load has lower impact resistance because the small force for penetration is needed.

In Figure 4 it is visible that the smaller impact force is needed for ABS penetration after humidity and temperature load. The difference is $959 \mathrm{~N}$. The similar material behaviour is also in Figure 5 where the all consumed work in $\mathrm{J}$ is displayed, there is the difference $3,5 \mathrm{~J}$.
In Figure 6 and 7 the up and side view before climate test is displayed. From the pictures it is clear that the growth of the main crack continuing around the edge occurs.

In Figure 8 and 9 the up and side view after climate test is displayed. In comparison with the crack growth before climate test it is visible, that after lowering of the impact resistance caused by temperature and humidity load the crack growth differs.

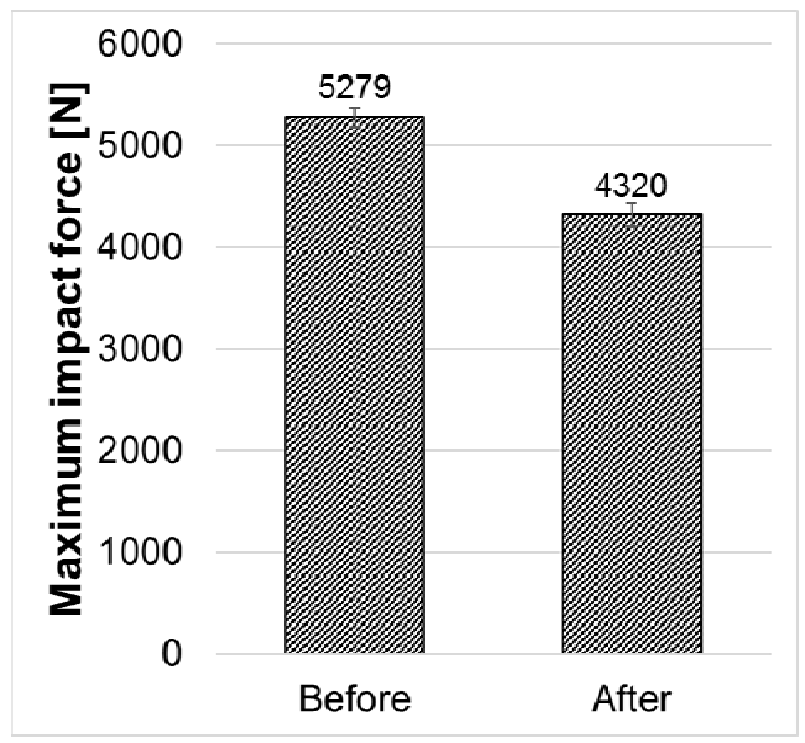

Fig. 4. ABS maximum impact force before and after temperature and humidity loading.

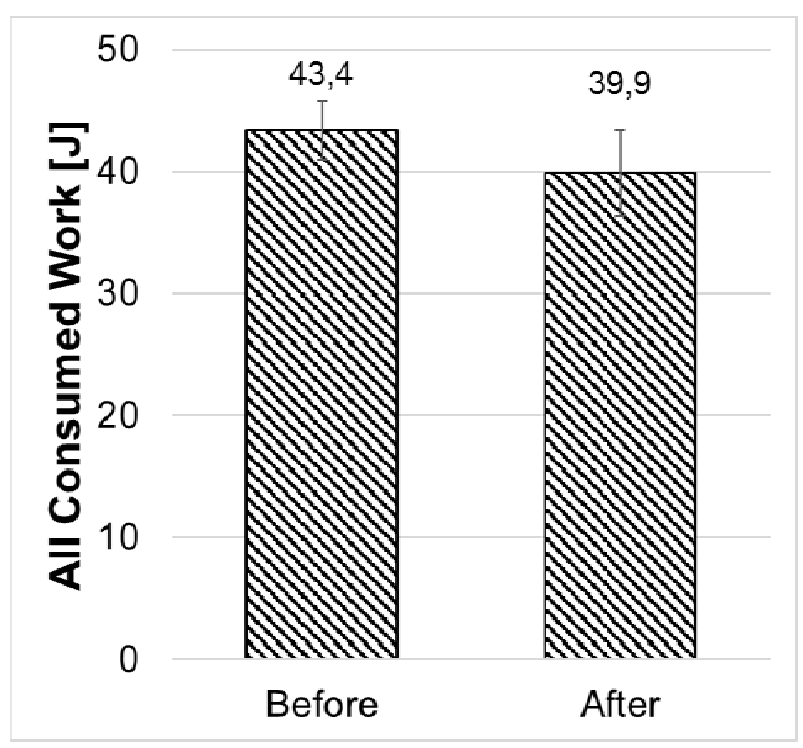

Fig. 5. ABS all consumed work before and after temperature and humidity loading. 


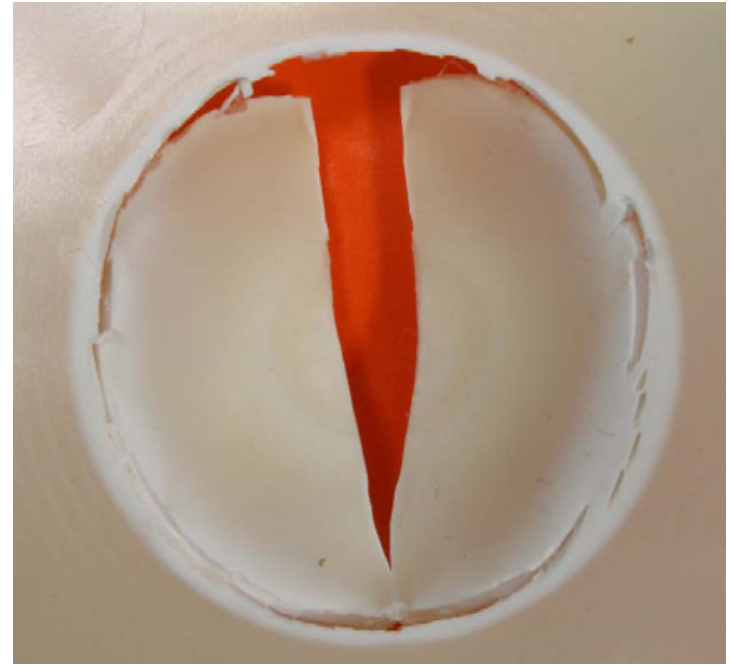

Fig. 6. ABS deformation after drop weight test at $100 \mathrm{~J}$ before climate test (up view).

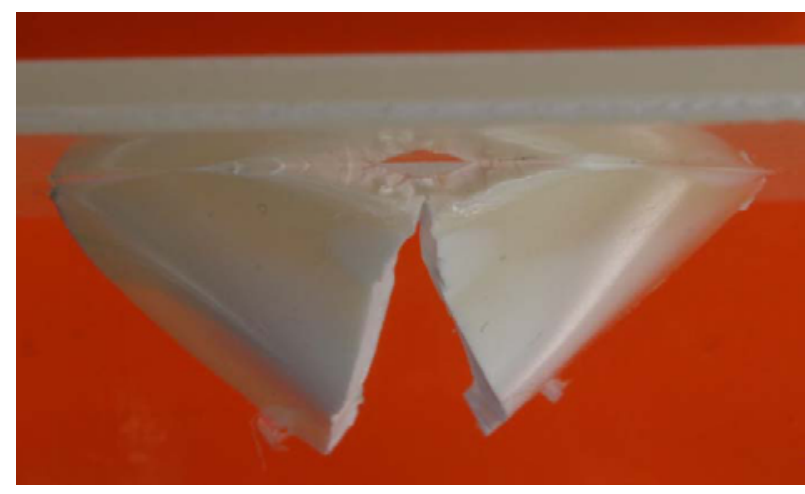

Fig. 7. ABS deformation after drop weight test at $100 \mathrm{~J}$ before climate test (side view).

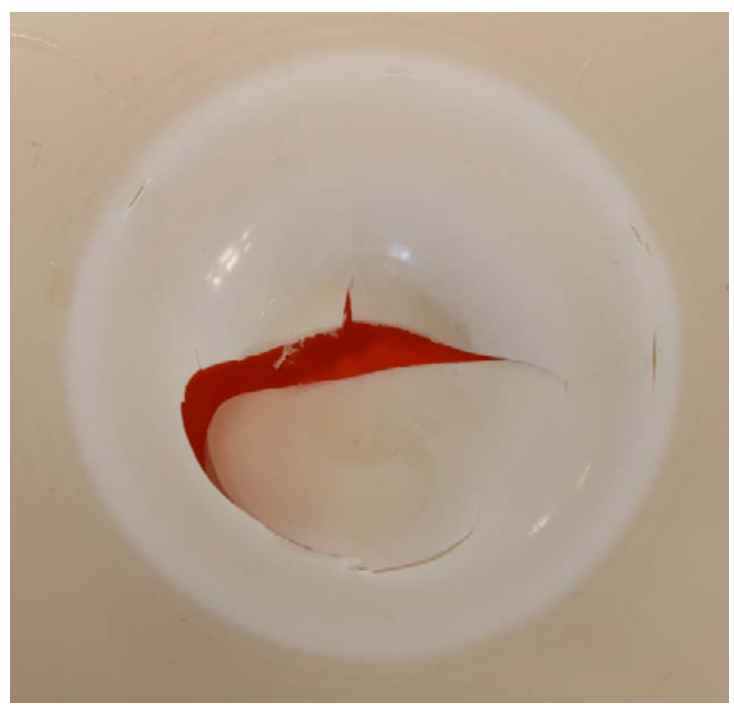

Fig. 8. ABS deformation after drop weight test at $100 \mathrm{~J}$ after climate test (up view).

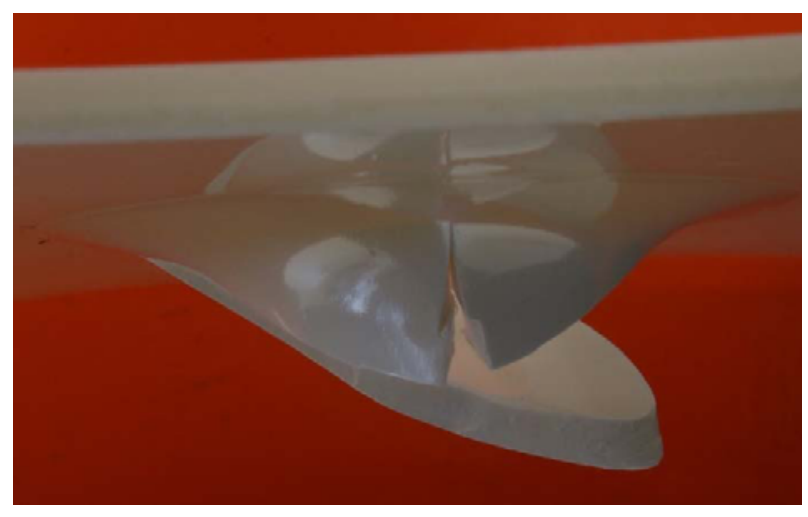

Fig. 9 ABS deformation after drop weight test at $100 \mathrm{~J}$ after climate test (side view).

\section{Summary}

In this study the injection moulded ABS samples were subjected the test of falling penetrator at fall height $100 \mathrm{~J}$ after and before temperature and humidity load. The results show that after 168 hours in environment at temperature $75{ }^{\circ} \mathrm{C}$ and humidity $98 \%$ the material does not have the same properties as before load. The impact resistance decreased significantly.

\section{Acknowledgment}

This paper is supported by the internal grant of TBU in Zlin No. IGA/FT/2017/010 funded from the resources of specific university research and by the Ministry of Education, Youth and Sports of the Czech Republic within the National Sustainability Programme project No. LO1303 (MSMT-7778/2014) and also by the European Regional Development Fund under the project CEBIATech No. CZ.1.05/2.1.00/03.0089.

\section{References}

1. H. Polli, L.A.M. Pontes, A.S. Araujo, J.M.F. Barros, V.J. Fernandes Jr., J. Therm. Anal. Calorim. 95 (2009), 131-134

2. S. Olivera, H.B. Muralidhara, K.Venkatesh, K. Gopalakrishna, C.S. Vivek, J. Mater. Sci. 51 (2016), 3657-3674

3. Y. Aoki, Chem. Phys. 7 (2017), 1935-2492“

4. F.L. Jin, S.L. Lu, Z.B. Song, J.X. Pang, L. Zhang, J.D. Sun, X.P. Cai, Mater. Sci. Eng., A 527 (2010), 3438-3441

5. M.A. Peydro, F. Parres, R. Navarro, S. SanchesCaballero, Polym. Eng. Sci. (2014), DOI 10.1002/pen.23680, 1313-1324

6. J. Yang, Ch.X. Wang, Z.S Yu, Y. Li, K.K. Yang, Y.Z. Wang, J. Appl. Polym. Sci. 121 (2011), 24582466

7. X.Y. Xu, X.F. Xu, Polym. Eng. Sci. (2011), DOI 10.1002/pen.21908, 902-907 